\title{
Wind waves: modeling and observations
}

\author{
A. D. Rao $\cdot$ J. W. de Vries
}

Published online: 9 January 2009

(C) Springer Science+Business Media B.V. 2009

Wind waves are a permanent feature of oceanic wave phenomena and pose a serious threat to safe navigation as well as to coastal defenses around the globe. We express our appreciation to the editors and publishers of Natural Hazards for inviting us to guest edit this special issue of the journal, which gives an overview of the current status of wave modeling and observations and the application to forecasts in vulnerable areas. We also thank the authors for their important and contemporary contributions and the various referees for their critical and constructive comments to enhance the quality of the submitted manuscripts. This issue has a total of 17 articles and can be viewed in broad terms as consisting of five topics under which the articles are arranged. Group one deals with theory and numerical modeling and the following articles come under this category.

- Estimation of wave period statistics using numerical coastal wave model.

- Parameterization of sea-surface drag under varying sea state and its dependence on wave age.

- Modified Weibull-derived spectrum for deep water significant wave height estimation.

- Effect of varied atmospheric stability on sea-surface drag in shallow seas and its impact on wind-wave growth.

Interaction of wind waves with tides and storm surges is in group two under the title interactions. Articles given below belong to this group.

- Impact of cyclonic wind field on surge computations using finite-element and finitedifference models.

- Coastal flooding-impacts of coupled wave-surge-tide models.

\footnotetext{
A. D. Rao (ه)

Centre for Atmospheric Sciences, Indian Institute of Technology Delhi, Hauz Khas,

New Delhi 110 016, India

e-mail: adrao@cas.iitd.ernet.in

J. W. de Vries

Royal Netherlands Meteorological Institute, P.O. Box 201, 3730 AE De Bilt, The Netherlands

e-mail: Hans.de.Vries@knmi.nl
} 
The third category is data and observations and articles mentioned below fall into this group.

- Optimal interpolation of buoy data into a deterministic wind-wave model.

- Improvement in predictability of waves over the Indian Ocean.

- Alternative data driven methods to estimate wind from waves by inverse modeling.

The fourth group is about regional studies and articles listed below are in this topic.

- Spectral characteristics of the nearshore waves off Paradip, India, during monsoon and extreme events.

- Wind waves and sediment transport regime off the south central Kerala coast, India.

- Significance of nearshore wave parameters in identifying vulnerable zones during storm and normal conditions along Visakhapatnam coast, India.

- High swell warnings in the Caribbean Islands during March 2008.

- Application of wave transformation models for estimation of morphological changes at Vellar Estuary, south east coast of India.

- Operational wave prediction of extreme storms in Northern Europe.

The fifth and final group is miscellaneous and articles given below are in this category.

- Experimental and numerical investigations on zigzag porous screen breakwater.

- Demarcation of inland vessels' limit off Mormugao Port region, India—a pilot study for the safety of inland vessels using wave modeling.

We hope that the readers of this journal will find this collection of articles on wind waves useful and informative. 